\title{
TUBERCULOMATA OF THE NOSE: REPORT OF TWO CASES.
}

\author{
By James Harper, M.A., M.B., F.R.F.P.S.G., \\ Surgeon-in-Charge, the Throat, Nose and Ear Department, Royal Hospital for Sick \\ Children, Glasgow ; Aural Surgeon to Out-Patients, Royal Infirmary, Glasgow.
}

THE occurrence of primary tuberculosis of the nose is so rare that I venture to hope the description of two cases which have been under my care may be of interest. These cases had much in common. Both were married men over middle age, and had reared large, healthy families, and neither in themselves nor in their family histories was there any evidence of tuberculosis.

The lesions were identical in both cases. In appearance they were the same, and occupied the same site in the nose, while the symptoms from which they suffered were similar. I had already treated the first case for nasal trouble which was non-tubercular, but the second case had never had any previous nasal trouble.

CASE 1. - I was first consulted by Mr. $\mathrm{H}-$, aged forty-six, about eight years ago. For about five years he had suffered from nasal polypi, which had been removed on several occasions by various surgeons. When I saw him both nostrils were blocked by polypi. I removed the polypi, along with portions of the necrotic ethmoids and parts of the inferior turbinate bone on each side. The operation had the desired effect. In about six weeks the nose was free of discharge, and there was no sign of any recurrence of the polypi. I lost sight of the case until the autumn of 1:13, when he again consulted me on account of nasal obstruction. He also complained of a profuse watery discharge with sneezing in the morning. The condition had gradually become worse during the previous four months. I suspected a return of the polypi, but on examination of the nose $I$ found the ethmoid region free of polypi. There was, however, a growth springing from each side of the septum, which completely blocked the air-passages. It originated from the septum at the junction of the cartilaginous septum with the maxillary ridge of the superior maxilla. The growth commenced just inside the nostril, and extended back for about an inch and a half. It was pedunculated and did not invade the surrounding mucous membrane. It was reddish-grey in colour, and of an uneven, mammilated appearance. The growth felt firm and resistant, with no tendency to bleeding when probed, nor was there any evidence of ulceration. In appearance and consistency it was similar to that found in cases of hypertrophy of the inferior turbinate bones, where the mucous membrane covering the lower edge of the bone has become greatly thickened and lobulated and hangs down towards the floor of the nose.

The patient chiefly complained of obstruction to the breathing. As regards his general condition he informed me that he had never felt better in his life, and he looked the picture of robust health.

I suggested the removal of a small portion of the growth for microscopic examination, but the patient desired immediate relief from the nasal obstruction. Under cocaine anæsthesia I cut off the growth at the base with a sharp knife, keeping well down on to the cartilage and bone in each nostril. I prescribed a soothing nasal ointment, intending to await the result of the examination of the specimen. The report of the growth showed that microscopically it presented a typical tubercular appearance. The epithelium covering it, though thin in one or two places, was intact. There were scattered masses of cells throughout the growth, with epithelioid and giant cells in the centre of the masses, but no tubercle bacilli were to be found.

I was greatly surprised to find that the nose healed rapidly and gave no further trouble. I watched the case carefully, expecting an early recurrence of the condition, but the site from which the growth sprang was soon covered by healthy tissue. I have seen the patient at intervals since. His health has never been better, and on examination of the nose $I$ can find no evidence of any further mischief.

CASE 2.-In the autumn of 1914 I was asked to see Mr. S-, aged forty-seven, by Dr. Neill. This patient had been complaining of nasal obstruction with a slight 
watery discharge for some six months. Examination of the nose revealed a growth in each nostril in exactly the same situation as in the previous case. It was the same size, and had the same appearance and consistency. There was this difference, however: the growth on the right side was very slightly ulcerated at its anterior end, and the mucous membrane on each side of the septum appeared to be infiltrated for about a quarter of an inch above the growth. The appearance of this portion of the mucous membrane was similar to that seen in early lupus of the nose before it has begun to ulcerate.

I removed a small portion of the growth from the right nostril, including the ulcerated area. Microscopically the growth was of the same character as in the first case, but Dr. Shaw Dunn reported that there were in addition numerous tubercle bacilli present in the tissue round the ulcerated area.

A few days later I removed the growth, taking with it the infiltrated mucous membrane. This I did by cutting out a portion of the septum and chiselling out the bone beneath the attachment of the growth. I insufflated some iodoform powder on to the surface of the exposed bone, and with this exception treated the case with my after-treatment for intra-nasal operations. The nose healed without any trouble, and a month later the area which had been operated upon was completely covered by healthy tissue. The discharge had stopped and no disease was apparent in the nostrils.

I have seen this case at intervals since, and the nose remains clean and healthy.

There are several unusual features common to both these cases. The growths were present in both nostrils. They healed rapidly without recurrence, and there was no tendency to bleeding. Most text-books tell us that nasal tuberculomata recur after operation, and that healing is always slow.

It is now five and a half years since I removed the growth in the first case, and four and a half years in the second case. The first patient is enjoying perfect health, and there is no sign of recurrence. The second case is of interest in that while the nasal condition remains healed the patient is at present in a sanatorium suffering from slight pulmonary tuberculosis.

\title{
THREE CASES OF ACCESSORY NASAL SINUS SUPPURATION.
}

\author{
By W. M. Mollison.
}

(1) Loss of Memory from the Presence of a Single Nasal Polyp.-The patient was a man, aged sixty, active mentally and physically. In April, 1916, he began to suffer from very severe frontal headache; the headache had wakened him regularly at 2 a.m. For three weeks he had been unable to attend to business on account of the pain.

For a few days he had complete loss of memory for intervals of a few hours. For example, his partner would come to discuss business; later, and after the interview, he would be astonished to hear that his partner had been, and could remember nothing about it.

A large nasopharyngeal polypus was seen and subsequently removed. Three days later the headache was much relieved, but the patient had complete loss of memory for four hours. The patient recovered completely and was able to resume business within a month.

Such a case might be of considerable medico-legal importance.

(2) Acute Sphenoidal Sinus Suppuration Simulating Acute Mastoiditis. -A lady, aged twenty-five, suffered from some nasal catarrh in February, 1918. A few days later she developed right-sided earache; she had a rigor, and the temperature rose to $105^{\circ} \mathrm{F}$. During the following week 